\title{
Retrospective evaluation of vector-borne pathogens in cats living in Germany (2012-2020)
}

Ingo Schäfer ${ }^{1,2^{*}}$, Barbara Kohn², Maria Volkmann ${ }^{3}$ and Elisabeth Müller ${ }^{1}$

\begin{abstract}
Background: Blood-feeding arthropods can transmit parasitic, bacterial, or viral pathogens to domestic animals and wildlife. Vector-borne infections are gaining significance because of increasing travel and import of pets from abroad as well as the changing climate in Europe. The main objective of this study was to assess the percentage of cats with positive test results for selected vector-borne pathogens in Germany and explore any possible association of such results with time spent abroad.
\end{abstract}

Methods: This retrospective study included test results from cats included in the "Feline Travel Profile" established by the LABOKLIN laboratory at the request of veterinarians in Germany between April 2012 and March 2020. This diagnostic panel includes the direct detection of Hepatozoon spp. and Dirofilaria spp. via PCR as well as indirect detection assays (IFAT) for Ehrlichia spp. and Leishmania spp. The panel was expanded to include an IFAT for Rickettsia spp. from July 2015 onwards.

Results: A total of 624 cats were tested using the "Feline Travel Profile." Serum for indirect detection assays was available for all 624 cats; EDTA samples for direct detection methods were available from 618 cats. Positive test results were as follows: Ehrlichia spp. IFAT 73 out of 624 (12\%), Leishmania spp. IFAT 22 out of 624 (4\%), Hepatozoon spp. PCR 53 out of 618 (9\%), Dirofilaria spp. PCR 1 out of 618 cats (0.2\%), and Rickettsia spp. IFAT 52 out of 467 cats (11\%) tested from July 2015 onwards. Three cats had positive test results for more than one pathogen before 2015. After testing for Rickettsia spp. was included in 2015, 19 cats had positive test results for more than one pathogen (Rickettsia spp. were involved in 14 out of these 19 cats).

Conclusions: At least one pathogen could be detected in 175 out of 624 cats (28\%) via indirect and/or direct detection methods. Four percent had positive test results for more than one pathogen. These data emphasize the importance of considering the above-mentioned vector-borne infections as potential differential diagnoses in clinically symptomatic cats.

Keywords: Arthropod-transmitted infections, Feline, Laboratory diagnostics

\section{Introduction}

Cats are exposed to blood-feeding arthropods such as fleas, ticks, or mosquitoes, especially outdoor or stray cats without ectoparasite prophylaxis [1, 2]. These

*Correspondence: ingo.schaefer@fu-berlin.de

${ }^{1}$ LABOKLIN GmbH and Co. KG, Bad Kissingen, Germany

Full list of author information is available at the end of the article vectors can transmit parasitic, bacterial, or viral pathogens, which may subsequently cause infection in competent hosts such as cats. The occurrence of feline infectious agents is influenced mainly by the distribution of competent vectors, e.g. areas with high prevalences of Leishmania spp. were associated with habitats of phlebotomine sand flies in the Mediterranean and Southeast Europe [3]. Hepatozoon spp. are transmitted by various

(c) The Author(s) 2021. This article is licensed under a Creative Commons Attribution 4.0 International License, which permits use, sharing, adaptation, distribution and reproduction in any medium or format, as long as you give appropriate credit to the original author(s) and the source, provide a link to the Creative Commons licence, and indicate if changes were made. The images or other third party material in this article are included in the article's Creative Commons licence, unless indicated otherwise in a credit line to the material. If material is not included in the article's Creative Commons licence and your intended use is not permitted by statutory regulation or exceeds the permitted use, you will need to obtain permission directly from the copyright holder. To view a copy of this licence, visit http://creativeco mmons.org/licenses/by/4.0/. The Creative Commons Public Domain Dedication waiver (http://creativecommons.org/publicdomain/ zero/1.0/) applies to the data made available in this article, unless otherwise stated in a credit line to the data. 
blood-feeding arthropods worldwide, including ticks, mites, sandflies, tsetse flies, lice, kissing bugs, and leeches $[4,5]$. Infections with $H$. felis or, less frequently, $H$. canis and $H$. silvestris have been detected in cats in the Mediterranean and Southeast Europe [4-8]. There are also single case reports of infections with $\mathrm{H}$. felis in Austria [9] and H. silvestris in Switzerland [8]. Infections with Dirofilaria spp., nematodes transmitted by mosquitoes, are less frequently reported in cats compared to dogs $[2,10]$. While infections with $D$. immitis generally occur within the Mediterranean and Southeast Europe, there has been just one case report of a cat infected with $D$. repens in Poland [11]. Rickettsia felis has been detected in fleas in Germany [12], and as such autochthonous infections in cats in Germany are possible. Other documented vector-borne pathogens affecting cats in Europe include helminths (Thelazia callipaeda, Dipylidium caninum), bacteria (Bartonella spp., Haemoplasma spp., Borrelia burgdorferi complex, Anaplasma (A.) phagocytophilum, A. platys, Coxiella burnetii, Francisella tularensis), protozoa (Babesia spp., and Cytauxzoon spp.), as well as viruses, namely Flaviviridae [2].

Among the pathogens examined in this study, Rickettsia spp., Leishmania spp., and Dirofilaria spp. have zoonotic potential and are consequently of importance for public health in Europe [2]. To the knowledge of the authors, there are presently no studies regarding the prevalence of antigens and/or antibodies to the vector-borne pathogens Leishmania spp., Ehrlichia spp, Rickettsia spp., Dirofilaria spp., and Hepatozoon spp. in cats in Germany. The aims of this study were to determine the percentage of positive test results for these vector-borne pathogens in cats for which samples were provided by veterinarians in Germany to the veterinary laboratory (Bad Kissingen, Germany) and to determine whether positive results were associated with a background history of time spent abroad.

\section{Methods}

This study included any "Feline Travel Profile" results of samples provided by veterinarians in Germany between April of 2012 and March of 2020. The panel includes a direct assay by polymerase chain reaction (PCR) of Hepatozoon spp. (TaqMan ${ }^{\circledR}$ real-time PCR, target: $18 \mathrm{~S}$ rRNA) and Dirofilaria spp. ((TaqMan ${ }^{\circledR}$ real-time PCR, target: 5.8S rDNA, based on Rishniw et al. [13]). Furthermore, it includes immunofluorescence antibody testing (IFAT) for Ehrlichia spp. (MegaFLUO $^{\circledR}$ EHRLICHIA canis, MegaCor Diagnostik GmbH, Hörbranz, Austria; $\geq 1: 40$ positive) and Leishmania spp. (MegaFLUO ${ }^{\circledR}$ LEISH, MegaCor Diagnostik GmbH, Hörbranz, Austria; > 1:64 positive) as well as
Rickettsia spp. (RICKETTSIA CONORII IFA SLIDE, Viracell, Granada, Spain; > 1:128 positive) from July 2015 onwards (Table 1). Where possible, information on time spent abroad was collected in questionnaires and telephone calls to the treating veterinarians. A descriptive statistical analysis of the data collected was made using SPSS for Windows (version 27.0, SPSS Inc., Armonk, NY, USA).

\section{Results}

\section{Signalment and stays abroad}

Six hundred twenty-four cats were included in this study. Information on the breed was provided for 554/624 cats (89\%). There were 20 different breeds of cats, predominantly European shorthairs (423/554 cats, $76 \%)$ as well as mixed breeds $(71 / 554$ cats, $13 \%)$ and Siamese cats $(17 / 554$ cats, $3 \%)$. The sex of the animal was indicated for $573 / 624$ cats (92\%); of these, $308 / 573$ cats (54\%) were male and 265/573 (46\%) female. The age of the animal was known in 536/624 cases (86\%), for whom the median age was 2 years (mean: 3.53 years; range: $0.2-18$ years).

Information on time spent abroad was either unavailable or could not be requested retrospectively for $253 / 624$ cats (41\%). Eight out of 624 cats (1\%) were born in Germany and had never traveled. A travel history was available for $363 / 624$ cats $(58 \%)$. This included 29 countries, of which Spain (158/363 cats, 44\%), Greece (53/363 cats, 15\%), and Romania (33/363 cats, 9\%) were most frequently named (Table 2). Among this group of cats, $356 / 363$ (98\%) were imported to Germany from abroad, of which 38 cats were imported by animal rescue organizations, and 15 cats were imported by private individuals after a holiday. One cat was imported from France and subsequently traveled to Turkey every year with its owner. Six of the 363 cats (2\%) were born in Germany and accompanied their owners on vacations abroad, during which they would be allowed to roam freely in the respective foreign country (Spain, $n=2$; France, Italy, Romania, Bosnia, each $n=1$ ).

\section{Laboratory diagnostics}

Results from 2951 direct and indirect detection assays on samples from 624 cats were evaluated. PCR testing was performed on samples from 618/624 cats (99.9\%) for both Hepatozoon spp. and Dirofilaria spp. For 6/624 cats $(0.1 \%)$, no EDTA blood was provided for analysis. Indirect testing via IFAT for Ehrlichia spp. and Leishmania spp. was performed for all 624 cats. After the addition of a Rickettsia spp. IFAT to the "Feline Travel Profile" in July $2015,467 / 624$ cats $(75 \%)$ were also tested for this pathogen.

One hundred seventy-five out of 624 cats $(28 \%)$ had positive test results for at least one of the pathogens 
(Table 1). PCR testing was reported as positive for Hepatozoon spp. in 53/618 cats (9\%) and for Dirofilaria spp. in $1 / 618$ cats $(0.2 \%)$. IFAT testing showed the following: $73 / 624$ cats (12\%) had positive serology for Ehrlichia spp., 52/467 cats (11\%) for Rickettsia spp., and 22/624 cats (4\%) for Leishmania spp. For Ehrlichia spp. serology, titers of 1:40 $(n=44), 1: 320(n=24)$, and 1:640 $(n=5)$ were detected. Antibodies to Rickettsia spp. were found in 52 cats, with titers of 1:256 $(n=33), 1: 512(n=14)$ and 1:1024 $(n=5)$. The 22 cats with antibodies to Leishmania spp. had titers of 1:128 $(n=14), 1: 256(n=3)$, $1: 512(n=4)$ and $1: 1024(n=1)$.

In $22 / 624$ cats (4\%), more than one pathogen was found by direct and/or indirect detection methods. This group includes three cats $(14 \%)$ with positive test results prior to the addition of Rickettsia spp. IFAT to the "Feline Travel Profile" (Leishmania spp. IFAT/Dirofilaria spp. PCR, Leishmania spp. IFAT/Hepatozoon spp. PCR, and Leishmania/Ehrlichia spp. IFAT) in July 2015 and 19/22 cats $(86 \%)$ after this addition. Rickettsia spp. were implicated in 14 of these 19 cats (74\%). Overall, 19 cats had two concurrent positive test results for different pathogens [Ehrlichia/Rickettsia spp. IFAT $(n=6)$; Leishmania/ Rickettsia spp. IFAT and Leishmania spp. IFAT/Hepatozoon spp. PCR ( $n=3$, respectively); Rickettsia spp. IFAT/ Hepatozoon spp. PCR, Ehrlichia spp. IFAT/Hepatozoon spp. PCR, and Ehrlichia/Leishmania spp. IFAT $(n=2$, respectively) as well as Leishmania spp. IFAT/Dirofilaria spp. PCR $(n=1)]$. Three cats had simultaneous positive test results for three pathogens [Ehrlichia/Leishmania/
Rickettsia spp. IFAT $(n=2)$, Leishmania spp. IFAT/Rickettsia spp. IFAT/Hepatozoon spp. PCR $(n=1)]$.

Among the 363 cats with a history of time spent abroad, $110(30 \%)$ had positive test results for at least one vector-borne pathogen. Three hundred twenty of the 363 cats $(88 \%)$ had been to a different country in the European Union, and 44 (12\%) had stayed in countries outside the European Union [primarily Turkey $(n=12)$ and Dubai $(n=5)$ ] (Table 2). One cat had been imported from France and subsequently accompanied its owner to Turkey every year, and it was thus included in both categories. Six cats were born in Germany and accompanied their owners on travels abroad, but all had entirely negative test results in this study. Test results were positive for more than two to three pathogens in $10 / 363$ cats (3\%), the majority of which had returned or came from Spain $(n=5)$ and Greece $(n=2)$.

There was a negative travel history in $8 / 624$ cats $(1 \%)$ tested by the "Feline Travel Profile." Four of these eight cats had antibodies for Rickettsia spp.

\section{Discussion}

This study investigated 624 cats in Germany for the presence of Hepatozoon spp. and Dirofilaria spp. via direct detection methods as well as for the presence of antibodies against Ehrlichia spp., Rickettsia spp., and Leishmania spp. via indirect detection methods. A background history was available for 371 cats, the majority of which had either been imported or had spent time outside of Germany (363/371 cats, 98\%). These numbers can be attributed to the fact that the testing panel used as the basis

Table 1 Results of the "Feline Travel Profile" diagnostic panel performed by the LABOKLIN laboratory (Bad Kissingen, Germany) in 624 cats from April 2012 until March 2020)

\begin{tabular}{|c|c|c|c|c|c|c|}
\hline Time period & Total n/N (\%) & $\begin{array}{l}\text { Hepatozoon } \\
\text { spp. }{ }^{\text {af }} \text { n/N (\%) }\end{array}$ & $\begin{array}{l}\text { Dirofilaria spp. }{ }^{b, f} \\
n / N(\%)\end{array}$ & Ehrlichia spp. ${ }^{\complement} n / N(\%)$ & $\begin{array}{l}\text { Leishmania } \\
\text { spp. }^{d} n / N(\%)\end{array}$ & Rickettsia spp. ${ }^{e, g} n / N(\%)$ \\
\hline 04/2012-03/2013 & $6 / 30(20)$ & $2 / 30(7)$ & $1 / 30(3)$ & $1 / 30(3)$ & $3 / 30(10)$ & - \\
\hline 04/2013-03/2014 & 15/47 (31.9) & $8 / 47(17)$ & $0 / 47(0)$ & 6/47 (13) & $2 / 47(4)$ & - \\
\hline 04/2014-03/2015 & 9/67 (13.4) & $3 / 67(5)$ & 0/67 (0) & 6/67 (9) & $1 / 67(2)$ & - \\
\hline 04/2015-03/2016 & $12 / 58(20.7)$ & $6 / 58(10)$ & 0/58 (0) & $2 / 58(3)$ & 2/58 (3) & $3 / 45(7)$ \\
\hline 04/2016-03/2017 & 19/87 (21.8) & $6 / 84(7)$ & 0/84 (0) & 3/87 (3) & 2/87 (2) & $11 / 87(13)$ \\
\hline 04/2017-03/2018 & 33/99 (33.3) & 8/98 (8) & 0/98 (0) & 10/99 (10) & 1/99 (1) & 14/99 (14) \\
\hline 04/2018-03/2019 & 44/98 (44.9) & 8/96 (8) & 0/96 (0) & 22/98 (22) & 8/98 (8) & 21/98 (21) \\
\hline 04/2019-03/2020 & $37 / 138(26.8)$ & $12 / 138(9)$ & $0 / 138$ & 23/138 (17) & $3 / 138(2)$ & $3 / 138(2)$ \\
\hline Total & $175 / 624(28)$ & $53 / 618(9)$ & $1 / 618(0.2)$ & $73 / 624(12)$ & $22 / 624(4)$ & $52 / 467(11)$ \\
\hline
\end{tabular}

\footnotetext{
${ }^{a}$ Polymerase chain reaction (PCR), TaqMan ${ }^{\circledR}$ real-time PCR, target: 18S rRNA

b PCR, based on Rishniw et al. [13]

c Immunoflourescent antibody test (IFAT), MegaFLUO ${ }^{\circledR}$ EHRLICHIA canis (MegaCor Diagnostik GmbH, Hörbranz, Austria; $\geq 1: 40$ positive)

d IFAT, MegaFLUO ${ }^{\circledR}$ LEISH (MegaCor Diagnostik GmbH, Hörbranz, Austria; > 1:64 positive)

e IFAT, RICKETTSIA CONORII IFA SLIDE (Viracell, Granada, Spain; > 1:128 positive)

${ }^{f}$ EDTA blood for PCR was not provided for $6 / 624$ cats

9 Testing for Rickettsia spp. was performed from 07/2015 onwards
} 
Table 2 Positive test results in 363 cats with known stays abroad and introduction of the "Feline Travel Profile" diagnostic panel from April 2012 until (and including) March 2020 in the LABOKLIN laboratory (Bad Kissingen, Germany)

\begin{tabular}{|c|c|c|c|c|c|c|c|c|}
\hline Country & N & $\begin{array}{l}N \text { tested } \\
\text { positive/N } \\
\text { total (\%) }\end{array}$ & $\begin{array}{l}\text { Hepatozoon } \\
\text { spp.c }^{c}\end{array}$ & $\begin{array}{l}\text { Dirofilaria } \\
\text { spp. }^{\text {d }}\end{array}$ & Ehrlichia spp. $^{\mathrm{e}}$ & Rickettsia spp., & $\begin{array}{l}\text { Leishmania } \\
\text { spp. }^{9}\end{array}$ & Stays abroad \\
\hline \multicolumn{9}{|c|}{ Countries of the European Union } \\
\hline Spain & 158 & $51 / 158(32)$ & 19 & - & 21 & 11 & 5 & $\begin{array}{l}131 \text { imports, } 20 \text { animal welfare imports, } \\
5 \text { imports after holidays, } 2 \text { holidays }\end{array}$ \\
\hline Greece & 52 & $17 / 52(33)$ & 8 & - & 7 & 2 & 2 & $\begin{array}{l}44 \text { imports, } 6 \text { animal welfare imports, } 2 \\
\text { imports after holidays }\end{array}$ \\
\hline Romania & 28 & $8 / 28(29)$ & 1 & - & 2 & 5 & 1 & $\begin{array}{l}26 \text { imports, } 1 \text { animal welfare imports, } \\
1 \text { holiday }\end{array}$ \\
\hline Bulgaria & 25 & $7 / 25(28)$ & 1 & - & 5 & 1 & - & $\begin{array}{l}18 \text { imports, } 6 \text { animal welfare imports, } 1 \\
\text { import after holidays }\end{array}$ \\
\hline Italy & 23 & $3 / 23(13)$ & - & - & - & 3 & - & $\begin{array}{l}20 \text { imports, } 1 \text { import after holidays, } 1 \\
\text { animal welfare import, } 1 \text { holiday }\end{array}$ \\
\hline Croatia & 15 & $3 / 15(20)$ & - & - & 2 & 1 & - & 11 imports, 4 imports after holidays \\
\hline Portugal & 9 & $2 / 9(22)$ & 1 & - & 1 & - & - & 8 imports, 1 animal welfare import \\
\hline France & $4^{\mathrm{B}}$ & $0 / 4(0)$ & - & - & - & - & - & 3 imports $^{\mathrm{a}} .1$ holiday \\
\hline Cyprus & 3 & $2 / 3(67)$ & 1 & - & 1 & - & - & 2 imports, 1 animal welfare imports \\
\hline Malta & 2 & $2 / 2(100)$ & 1 & - & 1 & - & - & 2 imports \\
\hline Slovenia & 1 & $0 / 1(0)$ & - & - & - & - & - & 1 import \\
\hline Total EU & $320^{b}$ & $95 / 320(30)$ & 32 & - & 40 & 23 & 8 & $\begin{array}{l}266 \text { imports, } 36 \text { animal welfare imports, } \\
13 \text { imports after holidays, } 5 \text { holidays }\end{array}$ \\
\hline Total Non-EU & $44^{\mathrm{a}}$ & $15 / 44(34)$ & 7 & - & - & 3 & 4 & $\begin{array}{l}39 \text { imports, } 2 \text { animal welfare imports, } 2 \\
\text { imports after holidays, } 1 \text { holiday }\end{array}$ \\
\hline
\end{tabular}

a Rickettsia spp. IFAT was added to the "Feline Travel Profil" from July 2015 onwards

b One cat which tested negative was imported from France and subsequently traveled to Turkey every year with its owner

c Polymerase chain reaction (PCR), TaqMan ${ }^{\circledR}$ real-time PCR, target: 18S rRNA

d PCR, based on Rishniw et al. 2006

e Immunoflourescent antibody test (IFAT), MegaFLUO ${ }^{\circledR}$ EHRLICHIA canis (MegaCor Diagnostik GmbH, Hörbranz, Austria; $\geq 1: 40$ positive)

f IFAT, RICKETTSIA CONORII IFA SLIDE (Viracell, Granada, Spain; > 1:128 positive)

9 IFAT, MegaFLUO ${ }^{\circledR}$ LEISH (MegaCor Diagnostik GmbH, Hörbranz, Austria; > 1:64 positive)

for this study to detect different vector-borne pathogens is offered as a "Feline Travel Profile" to veterinarians. The majority of the 363 cats with a known background history of time spent abroad had done so in other European countries $(88 \%)$, but several non-European countries were also implicated (22\%, Table 2). Spain $(n=158)$ and Greece $(n=52)$ were most commonly involved, and many of the cats with a background history implicating either one of these countries had positive test results (Spain: 32\%, Greece: 33\%). Imports by animal welfare organizations may play a significant role for both these countries (Spain: 20 animal welfare imports, Greece 6 animal welfare imports). Similarly, 6 out of 25 cats that had spent time in Bulgaria were imported to Germany by animal welfare organizations (Table 2). The number of imported cats greatly outweighs that of cats accompanying their owners' travels, which contrasts with the findings of previous studies in dogs $[14,15]$. The rising numbers of cats tested between 2012 and 2020 (Table 1) may indicate that the import of cats is gaining importance in Germany. Together with the change in climate in many parts of Europe, this could contribute to an increase in the spread of pathogens and their potential vectors into previously non-endemic areas such as Germany, where they may spread further and form reservoirs for infection. Under suitable conditions, pathogens transmitted by imported vectors may cause infection in competent hosts endemic to Germany, of which cats are only one example. Moreover, endemic vectors which are potentially competent may be infected with previously non-endemic pathogens during a bloodmeal on infected cats and could proceed to contribute to the spread of these pathogens. One example of this phenomenon are presently isolated cases of autochthonous infections with D. repens [16-18] and Leishmania infantum [19] in dogs in Germany.

To the knowledge of the authors, the prevalence of many vector-borne infectious pathogens in cats in Germany is still unknown, as for example for Hepatozoon spp. In this study, $9 \%$ of the cats tested for this pathogen 
had positive PCR results. Direct detection methods demonstrate the presence of deoxyribonucleic acid or the antigen of a pathogen. Apart from infections with $H$. canis and $H$. silvestris, $H$. felis seems to be the primary infecting pathogen in cats [20-25]. Species differentiation showed the presence of $H$. felis in $7 / 53$ cats infected with Hepatozoon spp. in this study. They had been imported from Spain $(n=5)$ and from Greece and Malta ( $n=1$ respectively), which is consistent with the above-cited literature. There is little knowledge about the pathogenesis, replication cycle, host range, and modes of transmission of Hepatozoon spp in cats. In addition to vector transmission, there are reports of transplacental transmission of $H$. canis and $H$. felis [6]. Therefore, any female cat that tested positive in this study and was not spayed $(n=7)$ could transmit the pathogen to its kittens in Germany, whether or not there was any contact with a vector. Autochthonous infection with $H$. felis has been reported in a cat in Austria [9]. This may indicate the spread of the pathogen and/or vectors from historically endemic countries in the Mediterranean to more northern regions of Central Europe. In this study, 39/53 cats with positive test results had a history of travel/import to a known endemic area, and time spent abroad could not be excluded for any of the animals with positive test results. Consequently, this study provides no evidence of autochthonous infections in cats within Germany.

One cat in this study had positive PCR results for Dirofilaria spp., but further species differentiation was not done, and a travel history or information on any time spent abroad was not available. This cat also had a positive IFAT for Leishmania spp., so contact with the pathogens in an endemic country in the Mediterranean is likely. Infections with Dirofilaria spp. in cats and dogs historically occur in Mediterranean countries but have recently spread within these countries, such as for example Italy, Spain, France, Greece, and Turkey [10]. Dirofilaria repens [26-28] has been the primary pathogen reported in Central and Eastern Europe, and it is currently considered an emerging zoonotic agent in all of Europe [29]. The prevalence of Dirofilaria spp. in cats varies from 0 to 33\% across Europe [11, 30-40]. According to predictive models developed for dirofilariasis, temperatures during the summer may be suitable for the life-cycle of larvae in mosquitoes even in colder regions like the UK, provided that reservoirs are present $[10,27,41,42]$. The true prevalence of $D$. immitis may be higher than indicated by the relatively low number of cats with positive test results in this study. Many of the immature pathogens are destroyed shortly after reaching the pulmonary arteries in cats, and the lifespan of the surviving pathogens is shorter in cats (2-4 years) than in most other species, such as dogs (5-7 years) [43]. Cats are rarely infected with more than five roundworms, which can be missed even in a post-mortem examination [44]. Microfilaremia is rare in cats, as fewer male worms are present [44]. Data on the prevalence of Dirofilaria spp. in cats in Germany are not yet available. A single case report from Central Europe describes a cat in Poland which was infected with D. repens and Wolbachia spp. [24].

Indirect detection methods were used to detect Ehrlichia spp., Rickettsia spp., and Leishmania spp. They only demonstrate the presence of antibodies produced in response to the pathogen contact, but not necessarily the presence of disease. It is generally possible to distinguish more recent infections from those in the past by means of simultaneous immunoglobulin $\mathrm{M}$ levels or paired serum samples taken at intervals of 2 to 4 weeks [45]. The indirect IFAT utilised in this study detected immunoglobulin $\mathrm{G}$ antibodies for all pathogens. Furthermore, the interpretation of IFAT can be subjective, so the sensitivity can be low, especially when titers are low or borderline. Limitations may also include the possibility of cross reactivity with other pathogens (e.g. between all Ehrlichia species [45]) as well as false-negative results in very young or immunosuppressed animals or where investigations were done early in the natural history of the disease and therefore prior to seroconversion [46]. Considering all limitations of antibody assays, positive results can be correlated with given antigen exposure.

The IFAT used in this study detected antibodies to Leishmania spp. in 22/624 cats (4\%). Cats in Mediterranean countries are generally infected by $L$. infantum. There is much variation in the reported prevalence of Leishmania spp. in cats tested by indirect assays not only between different European countries but also across different regions within one country, ranging from $0.1 \%$ to $60 \%[1,30,40,47-69]$. Currently, dogs are the only known primary reservoir of Leishmania spp. [70]. Sandflies can be infected with $L$. infantum during a bloodmeal on an infected cat. Therefore, cats may be instrumental in the spread of the pathogen in areas with a high prevalence [71], even though their role regarding the transmission cycle of the pathogen is still unknown [72]. The presence of competent vectors such as Phlebotomus perniciosus has been reported in the south of Germany [72], as has the potentially competent vector $P$. mascitti $[73,74]$. There is little evidence on the susceptibility or resistance of cats to natural infection. Cats have a more efficient T-helper 1 cell immune response compared to dogs, which may be the cause of the lower prevalence of the pathogen in cats [47]. Twelve out of the 22 cats with positive IFAT results (55\%) in this study were imported to Germany from Mediterranean countries and Southeast Europe, where $L$. infantum is endemic. One out of the 22 cats $(5 \%)$ was imported from Brazil, where cats may be 
infected by not only L. infantum but also L. amazonensis or L. braziliensis [75-78].

Antibodies against Ehrlichia spp. were detected via IFAT in $12 \%$ of the tested cats. Previous studies involving indirect detection methods (IFAT) report a $1-18 \%$ prevalence of Ehrlichia spp. in cats in the Mediterranean area [30, 51, 53, 55, 58, 79-83]. Data on the prevalence of antibodies against Ehrlichia spp. in cats in Germany are not currently available. IFAT may show some crossreactivity with $E$. chaffensis (found in cats in the US and Brazil) and E. ewingii (found in cats in the US) as well as with A. phagocytophilum and A. platys at lower titers. Cross-reactivity due to contact with $A$. phagocytophilum in Germany cannot be excluded, especially in the 44 cats with a low titer of 1:40 in this study.

Eleven percent of 467 cats had positive IFAT results for Rickettsia spp. Seroprevalence in cats has been reported in Italy, Spain, and Portugal (IFAT/ELISA: $0-48.7 \%$ ) [30, 47, 51, 53, 79, 84, 85]. Cats may be instrumental in the transmission cycle of some rickettsiae of the spotted fever group (SFG), especially $R$. conorii and $R$. felis [86, 87]. Antibodies for $R$. conorii have been detected in cats after infestation with Rhipicephalus sanguineus $[79,84,87]$, making vector contact in the Mediterranean most likely. Regarding R. felis, the situation differs: cats will have antibodies after being infected (either naturally or experimentally) with fleas of the species Ctenocephalides felis [88]. The pathogen has also been detected via PCR in previously non-infected fleas after a bloodmeal on infected cats [89]. Consequently, C. felis can be considered a competent vector, and autochthonous infections within Germany are possible. This study detected antibodies by means of IFAT, which is regarded as the gold standard for serological confirmation of pathogen contact in dogs and cats. There are, however, cross-reactions between any of the more than 20 species in the spotted fever group [87]. We detected antibodies to Rickettsia spp. in 52/467 cats (11\%). Twenty-nine cats were seropositive and had been imported from abroad, and it is unclear whether they were infected in Germany or in their country of origin. The four seropositive cats which had never left Germany were most likely infected with $R$. felis. The clinical importance of Rickettsia spp. infections in cats is still unknown. A study in clinically symptomatic cats found no association between positive antibody titers and fever, and no febrile cats in this study had positive PCR results for R. felis or R. rickettsi [90].

In this study, 22 out of 624 cats (4\%) had positive test results for more than one pathogen. It is known that coinfections may complicate diagnosis and treatment in dogs and may worsen their prognosis [2]. Coinfections with multiple vector-borne pathogens may occur in cats as well as dogs and humans, but their clinical consequences are still unknown and should be evaluated in further studies, especially in cats [45]. Nine cats infected with Hepatozoon spp. also had antibodies against Leishmania spp. $(n=4)$, Rickettsia spp. $(n=3)$, and Ehrlichia spp. $(n=2)$. Antibodies to Leishmania and Ehrlichia spp. were present in 12 cats infected with Hepatozoon spp., respectively. This indicates a pathogen contact with concurrent immunosuppression to be discussed in case of persistent infection, as it may result in increased susceptibility of infected animals to other pathogens [2].

\section{Limitations of this study}

Limitations of this study are mainly its retrospective design (e.g. no consistent histories) and the limited number of pathogens included. Certain vector-borne infectious pathogens such as Cytauxzoon spp. could not be included. Furthermore, species differentiation for specific pathogens included in the study was not performed, except in the case of seven cats with positive test results for $\mathrm{H}$. felis. There was also no information on the extent of ectoparasite prophylaxis in the cats, which may impact the prevalence of certain vectorborne pathogens. In the cats which had traveled with their owners to endemic countries, it was not possible to reliably document the duration or the time of the year of these travels. As many of the relevant vectors show pronounced seasonality, the time of year may significantly influence both incidence and prevalence of the pathogens they may transmit. The histories taken from the veterinarians only included the countries of stays abroad.

\section{Conclusions}

Of the cats included in this study, $28 \%$ had positive test results for at least one vector-borne pathogen. As vector-borne infections often remain undiagnosed, it is important to take thorough histories of any time spent abroad in all cats in which vector-transmitted infections are suspected. Owners of imported cats, or those who choose to take their cats with them on holidays abroad, should be given detailed information on any and all potential infections and resulting risks. Ectoparasite prophylaxis is advisable in all cats. The zoonotic potential of some pathogens such as L. infantum, $D$. immitis, and D. repens and their resulting importance in human medicine has to be noted [2]. 


\section{Abbreviations}

DAT: Direct agglutination test; DNA: Deoxyribonucleic acid; EDTA: Ethylenediaminetetraacetic acid; FeLV: Feline leukemia virus; FIV: Feline immunodeficiency virus; IFAT: Indirect immunofluorescence test; PCR: Polymerase chain reaction.

\section{Acknowledgements}

Not applicable.

\section{Authors' contributions}

IS collected and evaluated the data and wrote the manuscript. BK and EM initiated and supervised the study and edited the manuscript. MV supported the statistical analyses and edited the manuscript. All authors read and approved the final manuscript.

\section{Funding}

This research received no specific grant from any funding agency in the public, commercial, or not-for-profit sectors.

\section{Availability of data and materials}

All data generated or analyzed during this study are included in this published article. Parts of this study were presented as a poster at the DVG Congress for Internal Medicine and Laboratory Diagnostics in Gießen, Germany (30 January-01 February 2020) and as an oral presentation at the International Research Conference on Veterinary Parasitology and Entomology in Copenhagen, Denmark (11-12 June 2020, Online Congress).

\section{Ethics approval and consent to participate}

Not applicable.

\section{Consent for publication}

Not applicable.

\section{Competing interests}

The authors declare that they have no competing interests.

\section{Author details}

${ }^{1}$ LABOKLIN GmbH and Co. KG, Bad Kissingen, Germany. ${ }^{2}$ Clinic for Small Animals, Faculty of Veterinary Medicine, Freie Universität Berlin, Berlin, Germany. ${ }^{3}$ Institute of Veterinary Epidemiology and Biostatistics, Freie Universität Berlin, Berlin, Germany.

Received: 7 October 2020 Accepted: 6 February 2021

Published online: 25 February 2021

\section{References}

1. Otranto D, Napoli E, Latrofa MS, Annoscia G, Tarallo VD, Greco G, et al. Feline and canine leishmaniosis and other vector-borne diseases in the Aeolian Islands: Pathogen and vector circulation in a confined environment. Vet Parasitol. 2017;236:144-51.

2. ESCCAP. Control of vector-borne diseases in dogs and cats. Guidelines 05, 3rd ed. European Scientific Counsel Companion Animal Parasites; 2019.

3. latta R, Furlanello T, Colella V, Tarallo VD, Latrofa MS, Brianti E, et al. A nationwide survey of Leishmania infantum infection in cats and associated risk factors in Italy. PLoS Negl Trop Dis. 2019;13(7):e0007594.

4. Baneth G. Perspectives on canine and feline hepatozoonosis. Vet Parasitol. 2011;181(1):3-11.

5. Smith TG. The genus Hepatozoon (Apicomplexa: Adeleina). J Parasitol. 1996;82(4):565-85.

6. Baneth G, Sheiner A, Eyal O, Hahn S, Beaufils JP, Anug Y, et al. Redescription of Hepatozoon felis (Apicomplexa: Hepatozoidae) based on phylogenetic analysis, tissue and blood form morphology, and possible transplacental transmission. Parasit Vectors. 2013. https://doi. org/10.1186/1756-3305-6-102

7. Giannelli A, Latrofa MS, Nachum-Biala Y, Hodzic A, Greco G, Attanasi A, et al. Three different Hepatozoon species in domestic cats from southern Italy. Ticks Tick Borne Dis. 2017;8(5):721-4.
8. Kegler K, Nufer U, Alic A, Posthaus H, Olias P, Basso W. Fatal infection with emerging apicomplexan parasite Hepatozoon silvestris in a domestic cat. Parasit Vectors. 2018;11(1):428.

9. Basso W, Gorner D, Globokar M, Keidel A, Pantchev N. First autochthonous case of clinical Hepatozoon felis infection in a domestic cat in Central Europe. Parasitol Int. 2019;72:101945.

10. Pennisi MG, Tasker S, Hartmann K, Belak S, Addie D, Boucraut-Baralon $C$, et al. Dirofilarioses in cats: European guidelines from the ABCD on prevention and management. J Feline Med Surg. 2020;22(5):442-51.

11. Bajer A, Rodo A, Mierzejewska EJ, Tolkacz K, Welc-Faleciak R. The prevalence of Dirofilaria repens in cats, healthy dogs and dogs with concurrent babesiosis in an expansion zone in central Europe. BMC Vet Res. 2016:12(1):183.

12. Gilles J, Just FT, Silaghi C, Pradel I, Passos LM, Lengauer H, et al. Rickettsia felis in fleas. Germany Emerg Infect Dis. 2008;14(8):1294-6.

13. Rishniw M, Barr SC, Simpson KW, Frongillo MF, Franz M, Dominguez Alpizar JL. Discrimination between six species of canine microfilariae by a single polymerase chain reaction. Vet Parasitol. 2006;135(3-4):303-14.

14. Schäfer I, Volkmann M, Beelitz P, Müller E, Merle R, Kohn B. Retrospective analysis of vector-borne infections in dogs after travelling to endemic areas (2007-2018). Vet Parasitol X. 2019;2:100015.

15. Schäfer I, Volkmann M, Beelitz P, Merle R, Müller E, Kohn B. Retrospective evaluation of vector-borne infections in dogs imported from the Mediterranean region and southeastern Europe (2007-2015). Parasit Vectors. 2019;12(1):30.

16. Hermosilla C, Pantchev N, Dyachenko V, Gutmann M, Bauer C. First autochthonous case of canine ocular Dirofilaria repens infection in Germany. Vet Rec. 2006;158(4):134-5.

17. Pantchev N, Norden N, Lorentzen L, Rossi M, Rossi U, Brand B, et al. Current surveys on the prevalence and distribution of Dirofilaria spp. in dogs in Germany. Parasitol Res. 2009:105(Suppl 1):63-74.

18. Sassnau R, Dyachenko V, Pantchev N, Stockel F, Dittmar K, Daugschies A. Dirofilaria repens infestation in a sled dog kennel in the federal state of Brandenburg (Germany) Diagnosis and therapy of canine cutaneous dirofilariosis. Tieraerztl Prax K H. 2009:37(2):95-101 (In German).

19. Kellermeier C, Burger M, Werner H, Schein E, Kohn B. Autochthonous leishmaniosis in two Golden Retriever dogs from Brandenburg (Germany). Kleintierpraxis. 2007;52(10):649-53 (In German).

20. Tabar MD, Altet L, Francino O, Sanchez A, Ferrer L, Roura X. Vector-borne infections in cats: molecular study in Barcelona area (Spain). Vet Parasitol. 2008;151(2-4):332-6.

21. Ortuno A, Castella J, Criado-Fornelio A, Buling A, Barba-Carretero JC Molecular detection of a Hepatozoon species in stray cats from a feline colony in North-eastern Spain. Vet J. 2008;177(1):134-5.

22. Vilhena H, Martinez-Diaz VL, Cardoso L, Vieira L, Altet L, Francino O, et al. Feline vector-borne pathogens in the north and centre of Portugal. Parasit Vectors. 2013;6:99

23. Maia C, Ramos C, Coimbra M, Bastos F, Martins A, Pinto P, et al. Bacterial and protozoal agents of feline vector-borne diseases in domestic and stray cats from southern Portugal. Parasit Vectors. 2014;7:115.

24. Criado-Fornelio A, Buling A, Pingret JL, Etievant M, Boucraut-Baralon C, Alongi $A$, et al. Hemoprotozoa of domestic animals in France: prevalence and molecular characterization. Vet Parasitol. 2009;159(1):73-6.

25. Hodzic A, Alic A, Duscher GG. High diversity of blood-associated parasites and bacteria in European wild cats in Bosnia and Herzegovina: a molecular study. Ticks Tick Borne Dis. 2018;9(3):589-93.

26. Traversa D, Aste G, Milillo P, Capelli G, Pampurini F, Tunesi C, et al. Autochthonous foci of canine and feline infections by Dirofilaria immitis and Dirofilaria repens in central Italy. Vet Parasitol. 2010;169(1-2):128-32.

27. Genchi C, Kramer LH, Rivasi F. Dirofilarial infections in Europe. Vector Borne Zoonotic Dis. 2011;11(10):1307-17.

28. Morchon R, Carreton E, Gonzalez-Miguel J, Mellado-Hernandez I. Heartworm disease (Dirofilaria immitis) and their vectors in Europe-new distribution trends. Front Physiol. 2012;3:196.

29. Capelli G, Genchi C, Baneth G, Bourdeau P, Brianti E, Cardoso L, et al. Recent advances on Dirofilaria repens in dogs and humans in Europe. Parasit Vectors. 2018;11(1):663.

30. Morelli S, Crisi PE, Di Cesare A, De Santis F, Barlaam A, Santoprete G, et al. Exposure of client-owned cats to zoonotic vector-borne pathogens: Clinic-pathological alterations and infection risk analysis. Comp Immunol Microb. 2019:66:101344. 
31. Giangaspero A, Marangi M, Latrofa MS, Martinelli D, Traversa D, Otranto $D$, et al. Evidences of increasing risk of dirofilarioses in southern Italy. Parasitol Res. 2013;112(3):1357-61.

32. Di Cesare A, Castagna G, Meloni S, Milillo P, Latrofa S, Otranto D, et al. Canine and feline infections by cardiopulmonary nematodes in central and southern Italy. Parasitol Res. 2011;109(Suppl 1):S87-96.

33. Kramer L, Genchi C. Feline heartworm infection: serological survey of asymptomatic cats living in northern Italy. Vet Parasitol. 2002:104(1):43-50.

34. Montoya-Alonso JA, Morchon R, Falcon-Cordon Y, Falcon-Cordon S, Simon F, Carreton E. Prevalence of heartworm in dogs and cats of Madrid, Spain. Parasit Vectors. 2017;10(1):354.

35. Montoya-Alonso JA, Carreton E, Morchon R, Silveira-Viera L, Falcon $Y$, Simon F. The impact of the climate on the epidemiology of Dirofilaria immitis in the pet population of the Canary Islands. Vet Parasitol. 2016;216:66-71

36. Montoya-Alonso JA, Carreton E, Corbera JA, Juste MC, Mellado I, Morchon $\mathrm{R}$, et al. Current prevalence of Dirofilaria immitis in dogs, cats and humans from the island of Gran Canaria Spain. Vet Parasitol. 2011;176(4):291-4.

37. Diakou A, Soubasis N, Chochlios T, Oikonomidis IL, Tselekis D, Koutinas C, et al. Canine and feline dirofilariosis in a highly enzootic area: first report of feline dirofilariosis in Greece. Parasitol Res. 2019;118(2):677-82.

38. Vieira L, Silvestre-Ferreira AC, Fontes-Sousa AP, Balreira AC, Morchon R,

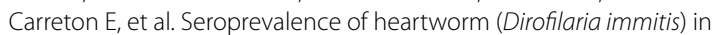
feline and canine hosts from central and northern Portugal. J Helminthol. 2015;89(5):625-9.

39. Maia C, Ramos C, Coimbra M, Cardoso L, Campino L. Prevalence of Dirofilaria immitis antigen and antibodies to Leishmania infantum in cats from southern Portugal. Parasitol Int. 2015;64(2):154-6.

40. Silaghi C, Knaus M, Rapti D, Kusi I, Shukullari E, Hamel D, et al. Survey of Toxoplasma gondii and Neospora caninum, haemotropic mycoplasmas and other arthropod-borne pathogens in cats from Albania. Parasit Vectors. 2014;7:62.

41. Venco L, Genchi M, Genchi C, Gatti D, Kramer L. Can heartworm prevalence in dogs be used as provisional data for assessing the prevalence of the infection in cats? Vet Parasitol. 2011;176(4):300-3.

42. Genchi C, Rinaldi L, Mortarino M, Genchi M, Cringoli G. Climate and Dirofilaria infection in Europe. Vet Parasitol. 2009;163(4):286-92.

43. McCall JW, Genchi C, Kramer LH, Guerrero J, Venco L. Heartworm disease in animals and humans. Adv Parasitol. 2008;66:193-285.

44. Ryan WG, Newcomb KM. Prevalence of feline heartworm disease - A global review. Proceedings of the Heartworm Symposium 1995; American Heartworm Society; 1995:79-86 [Conference Proceeding].

45. Pennisi MG, Hofmann-Lehmann R, Radford AD, Tasker S, Belak S, Addie DD, et al. Anaplasma, Ehrlichia and Rickettsia species infections in cats: European guidelines from the ABCD on prevention and management. J Feline Med Surg. 2017;19(5):542-8.

46. Solano-Gallego L, Villanueva-Saz S, Carbonell M, Trotta M, Furlanello T, Natale A. Serological diagnosis of canine leishmaniosis: comparison of three commercial ELISA tests (Leiscan, ID Screen and Leishmania 96), a rapid test (Speed Leish K) and an in-house IFAT. Parasit Vectors. 2014;7:111.

47. Morganti G, Veronesi F, Stefanetti V, Di Muccio T, Fiorentino E, Diaferia M, et al. Emerging feline vector-borne pathogens in Italy. Parasit Vectors. 2019;12(1):193.

48. Attipa C, Papasouliotis K, Solano-Gallego L, Baneth G, Nachum-Biala Y,

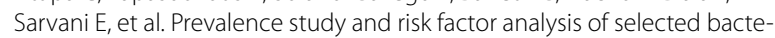
rial, protozoal and viral, including vector-borne, pathogens in cats from Cyprus. Parasit Vectors. 2017;10(1):130

49. Pennisi M, Lupo T, Malara D, Masucci M, Migliazzo A, Lombardo G. Serological and molecular prevalence of Leishmania infantum infection in cats from Southern Italy. J Feline Med Surg. 2012;14:656-7.

50. Spada E, Proverbio D, Migliazzo A, Della Pepa A, Perego R, De Bagnagatti Giorgi G. Serological and molecular evaluation of Leishmania infantum infection in stray cats in a nonendemic area in northern Italy. ISRN Parasitol. 2013. https://doi.org/10.5402/2013/916376.

51. Persichetti MF, Pennisi MG, Vullo A, Masucci M, Migliazzo A, SolanoGallego L. Clinical evaluation of outdoor cats exposed to ectoparasites and associated risk for vector-borne infections in southern Italy. Parasit Vectors. 2018;11(1):136.
52. Dedola C, Zobba R, Varcasia A, Visco S, Alberti A, Pipia AP, et al. Serological and molecular detection of Leishmania infantum in cats of Northern Sardinia Italy. Vet Parasitol Reg Stud Rep. 2018;13:120-3.

53. Persichetti MF, Solano-Gallego L, Serrano L, Altet L, Reale S, Masucci M, et al. Detection of vector-borne pathogens in cats and their ectoparasites in southern Italy. Parasit Vectors. 2016;9:247.

54. Veronesi F, Moretta I, Vitale F, Lupo T, Migliazzo A, Mariani C: Leishmania infantum: serological and molecular investigation in cats from Ischia island. In: 2nd International Congress on Canine Leishmaniasis 2010; Pisa: 169-71 [Conference Proceeding].

55. Vita S, Santori D, Aguzzi I, Petrotta E, Luciani A. Feline leishmaniasis and ehrlichiosis: serological investigation in Abruzzo region. Vet Res Commun 2005:29(Suppl 2):319-21.

56. Poli A, Abramo F, Barsotti P, Leva S, Gramiccia M, Ludovisi A, et al. Feline leishmaniosis due to Leishmania infantum in Italy. Vet Parasitol. 2002;106(3):181-91.

57. Miro G, Ruperez C, Checa R, Galvez R, Hernandez L, Garcia M, et al. Current status of $L$. infantum infection in stray cats in the Madrid region (Spain): implications for the recent outbreak of human leishmaniosis? Parasit Vectors. 2014;7:112.

58. Ayllon T, Diniz PP, Breitschwerdt EB, Villaescusa A, Rodriguez-Franco F, Sainz A. Vector-borne diseases in client-owned and stray cats from Madrid Spain. Vector Borne Zoonotic Dis. 2012;12(2):143-50.

59. Miro G, Hernandez L, Montoya A, Arranz-Solis D, Dado D, Rojo-Montejo S, et al. First description of naturally acquired Tritrichomonas foetus infection in a Persian cattery in Spain. Parasitol Res. 2011;109(4):1151-4.

60. Solano-Gallego L, Rodriguez-Cortes A, Iniesta L, Quintana J, Pastor J, Espada Y, et al. Cross-sectional serosurvey of feline leishmaniasis in ecoregions around the Northwestern Mediterranean. Am J Trop Med Hyg. 2007;76(4):676-80.

61. Martin-Sanchez J, Acedo C, Munoz-Perez M, Pesson B, Marchal O, Morillas-Marquez F. Infection by Leishmania infantum in cats: epidemiological study in Spain. Vet Parasitol. 2007;145(3-4):267-73.

62. Portús M, Gállego M, Riera C, Aisa M, Fisa R, Castillejo S. Wild and domestic mammals in the life cycle of Leishmania infantum in Southwest Europe. A literature review and studies performed in Catalonia (Spain). Rev Iber Parasitol. 2002;62:72-6.

63. Chatzis MK, Leontides L, Athanasiou LV, Papadopoulos E, Kasabalis D, Mylonakis $M$, et al. Evaluation of indirect immunofluorescence antibody test and enzyme-linked immunosorbent assay for the diagnosis of infection by Leishmania infantum in clinically normal and sick cats. Exp Parasitol. 2014;147:54-9.

64. Huebner J, Muller E, Langbein-Detsch I, Naucke T. Serological survey of Leishmania infections in cats from North Greece. J Vet Intern Med. 2008;22(3):782-3

65. Diakou A, Papadopoulos E, Lazarides K. Specific anti-Leishmania spp. antibodies in stray cats in Greece. J Feline Med Surg. 2009;11(8):728-30.

66. Duarte A, Castro I, da Fonseca IMP, Almeida V, de Carvalho LMM, Meireles $J$, et al. Survey of infectious and parasitic diseases in stray cats at the Lisbon Metropolitan Area Portugal. J Feline Med Surg. 2010;12(6):441-6.

67. Cardoso L, Lopes AP, Sherry K, Schallig H, Solano-Gallego L. Low seroprevalence of Leishmania infantum infection in cats from northern Portugal based on DAT and ELISA. Vet Parasitol. 2010;174(1-2):37-42.

68. Maia C, Gomes J, Cristovao J, Nunes M, Martins A, Rebelo E, et al. Feline Leishmania infection in a canine leishmaniasis endemic region Portugal. Vet Parasitol. 2010;174(3-4):336-40.

69. Maia C, Nunes M, Campino L. Importance of cats in zoonotic leishmaniasis in Portugal. Vector Borne Zoonotic Dis. 2008;8(4):555-9.

70. Quinnell RJ, Courtenay O. Transmission, reservoir hosts and control of zoonotic visceral leishmaniasis. Parasitology. 2009;136(14):1915-34.

71. Maia C, Campino L. Can domestic cats be considered reservoir hosts of zoonotic leishmaniasis? Trends Parasitol. 2011;27(8):341-4.

72. Otranto D, Cantacessi C, Pfeffer M, Dantas-Torres F, Brianti E, Deplazes $P$, et al. The role of wild canids and felids in spreading parasites to dogs and cats in Europe. Part I: Protozoa and tick-borne agents. Vet Parasitol. 2015;213(1-2):12-23.

73. Melaun C, Kruger A, Werblow A, Klimpel S. New record of the suspected leishmaniasis vector Phlebotomus (Transphlebotomus) mascittii Grassi, 1908 (Diptera: Psychodidae: Phlebotominae)-the northernmost phlebotomine sandfly occurrence in the Palearctic region. Parasitol Res. 2014;113(6):2295-301. 
74. Obwaller AG, Karakus M, Poeppl W, Toz S, Ozbel Y, Aspock H, et al. Could Phlebotomus mascittii play a role as a natural vector for Leishmania infantum? New data. Parasit Vectors. 2016;9:458.

75. de Souz AI, Barros EMS, Ishikawa E, Ilha IMN, Marin GRB, Nunes VLB. Feline leishmaniasis due to Leishmania (Leishmania) amazonensis in Mato Grosso do Sul State. Brazil Vet Parasitol. 2005;128(1-2):41-5.

76. Schubach TMP, Figueiredo FB, Pereira SA, Madeira MF, Santos IB, Andrade $M V$, et al. American cutaneous leishmaniasis in two cats from Rio de Janeiro, Brazil: first report of natural infection with Leishmania (Viannia) braziliensis. T Roy Soc Trop Med H. 2004;98(3):165-7.

77. Savani ES, de Oliveira Camargo MC, de Carvalho MR, Zampieri RA, dos Santos MG, D'Auria SR, et al. The first record in the Americas of an autochthonous case of Leishmania (Leishmania) infantum chagasi in a domestic cat (Felix catus) from Cotia County, Sao Paulo State Brazil. Vet Parasitol. 2004;120(3):229-33.

78. da Silva AV, de Souza Candido CD, de Pita PD, Brazil RP, Carreira JC. The first record of American visceral leishmaniasis in domestic cats from Rio de Janeiro. Brazil Acta Trop. 2008;105(1):92-4.

79. Solano-Gallego L, Hegarty B, Espada Y, Llull J, Breitschwerdt E. Serological and molecular evidence of exposure to arthropod-borne organisms in cats from northeastern Spain. Vet Microbiol. 2006;118(3-4):274-7.

80. Ebani WV, Bertelloni F. Serological evidence of exposure to Ehrlichia canis and Anaplasma phagocytophilum in Central Italian healthy domestic cats. Ticks Tick Borne Dis. 2014;5(6):668-71.

81. Ayllon T, Villaescusa A, Tesouro MA, Sainz A. Serology, PCR and culture of Ehrlichia/Anaplasma species in asymptomatic and symptomatic cats from central Spain. Clin Microbiol Infect. 2009;15(Suppl 2):4-5.

82. Ortuno A, Gauss CB, Garcia F, Gutierrez JF. Serological evidence of Ehrlichia spp. exposure in cats from northeastern Spain. J Vet Med B Infect Dis Vet Public Health. 2005;52(5):246-8.

83. Aguirre E, Tesouro MA, Amusategui I, Rodriguez-Franco F, Sainz A. Assessment of feline ehrlichiosis in central Spain using serology and a polymerase chain reaction technique. Ann N Y Acad Sci. 2004;1026:103-5.
84. Alves AS, Milhano N, Santos-Silva M, Santos AS, Vilhena M, de Sousa R. Evidence of Bartonella spp., Rickettsia spp. and Anaplasma phagocytophilum in domestic, shelter and stray cat blood and fleas. Portugal Clin Microbiol Infect. 2009;15(Suppl 2):1-3.

85. Nogueras MM, Pons I, Ortuno A, Miret J, Pla J, Castella J, et al. Molecular detection of Rickettsia typhi in cats and fleas. PLoS ONE. 2013;8(8):e71386.

86. Matthewman L, Kelly P, Hayter D, Downie S, Wray K, Bryson N. Domestic cats as indicators of the presence of spotted fever and typhus group rickettsiae. Eur J Epidemiol. 1997;13:109-11.

87. Segura F, Pons I, Miret J, Pla J, Ortuno A, Nogueras MM. The role of cats in the eco-epidemiology of spotted fever group diseases. Parasit Vectors. 2014;7:353.

88. Case JB, Chomel B, Nicholson W, Foley JE. Serological survey of vectorborne zoonotic pathogens in pet cats and cats from animal shelters and feral colonies. J Feline Med Surg. 2006;8(2):111-7.

89. Wedincamp J Jr, Foil LD. Infection and seroconversion of cats exposed to cat fleas (Ctenocephalides felis Bouche) infected with Rickettsia felis. J Vector Ecol. 2000;25(1):123-6.

90. Bayliss DB, Morris AK, Horta MC, Labruna MB, Radecki SV, Hawley JR, et al. Prevalence of Rickettsia species antibodies and Rickettsia species DNA in the blood of cats with and without fever. J Feline Med Surg. 2009; 11(4):266-70.

\section{Publisher's Note}

Springer Nature remains neutral with regard to jurisdictional claims in published maps and institutional affiliations.
Ready to submit your research? Choose BMC and benefit from:

- fast, convenient online submission

- thorough peer review by experienced researchers in your field

- rapid publication on acceptance

- support for research data, including large and complex data types

- gold Open Access which fosters wider collaboration and increased citations

- maximum visibility for your research: over $100 \mathrm{M}$ website views per year

At BMC, research is always in progress.

Learn more biomedcentral.com/submissions 